\title{
Ethical and normative implications of weather event attribution for policy discussions concerning loss and damage
}

\author{
Allen Thompson ${ }^{1 *}$ and Friederike E.L. Otto ${ }^{2}$ \\ ${ }^{1}$ School of History, Philosophy and Religion, Oregon State University, 322 Milam Hall,97331 \\ Corvallis, Oregon, USA. \\ ${ }^{2}$ Environmental Change Institute (ECI), University of Oxford, OX1 3QY, Oxford, UK. \\ *Allen.Thompson@oregonstate.edu

\begin{abstract}
Extreme weather events, at least in the short term, will arguably cause more damage and thus adversely affect society more than long term changes in the mean climate that are attributed to anthropogenic greenhouse gas emissions.

While it was long perceived as impossible to directly link a singular event with external climate drivers the emerging science of probabilistic event attribution render it possible to attribute the fraction of risk caused by anthropogenic climate change to particular weather events and their associated losses. Even with high uncertainty the robust link of only a small fraction of excessive deaths in, e.g., a heatwave to man-made climate change is from an ethical point of view very significant and we argue that this has widespread implications, e.g. for pending policy decisions concerning the Warsaw International Mechanism for Loss and Damage and the recognition of such losses in the broader context of climate justice.
\end{abstract}

Key words: event attribution, climate justice, extreme events, climate impacts 


\section{Introduction}

Human influence on the global climate system is unequivocal. A world with rising mean global temperatures is also a world of increasing high impact extreme weather events, including dangerous heat waves and droughts (Field et al., 2012). For example, the deaths of at least thirty-five thousand people in Europe are attributable to the recordbreaking heat wave of 2003 (Bhattacharya 2003). And things are only going to get worse. Britain's Committee on Climate Change recently predicted that by 2050 heat waves in England could cause a tripling of premature deaths, bringing the number up to seven thousand per year (Spross 2014). In the United States during the summer of 2014, all of California - the world's eighth largest economy - was under a severe drought with $\sim 82 \%$ of the state in an extreme drought and $\sim 58 \%$ of the state under conditions of exceptional drought. ${ }^{1}$ Thus, extreme heat waves and subsequent droughts can be directly linked to the loss of human life as well as damage to economic productivity. What if we could attribute such extreme weather events, and subsequently the resulting loss and damages, to anthropogenic climate change?

Two points are crucial here. First, the science of attributing slow-onset phenomena, such as higher mean temperatures and rising sea levels, is different than the science of attributing particular extreme weather events, such as heat waves, droughts, and extreme rainfall, to anthropogenic global climate change. The attribution of such extreme events requires a different statistical approach (Bindoff et al., 2013). Second, extreme events, at least in the short term, are likely to cause more loss and damage and thus adversely affect society more than slow-onset phenomena. If harmful weather extremes can be attributed to anthropogenic climate change, this could bring a lot of needed attention to the severity and danger associated with humanity's unfolding climate crisis.

While there is widespread agreement that slow-onset affects can be reliably attributed to greenhouse gas emissions and other anthropogenic atmospheric forcings, there is much less agreement about our ability to attribute any particular extreme weather to climate change (e.g. Trenberth, 2012). Neither a change in the probability of occurrence of a particular type of observed weather event nor the claim that such type of events will occur more frequently in the future is implied by the evidence that climate change is anthropogenic (Stott et al. 2013).

While it may seem clear that particular types of weather events, such as extreme precipitation, would become both more intense and more frequent with a rising mean global temperature, such general physical reasoning (e.g., warmer air can contain more water vapor leading to more intense and more frequent rainfall events) leaves us unable to say more than an increase in such extreme events is consistent with climate change (Hulme $2014,5)$. Furthermore, while higher temperatures lead to increased precipitation on a global scale, regional climates may become much drier due to changes in the circulation. Indeed, many have thought we may never be able to confidently attribute the cause of a

${ }^{1}$ http://droughtmonitor.unl.edu/Home/StateDroughtMonitor.aspx?CA (accessed July 31 2014) 
particular event to climate change because any particular storm might have occurred due to natural variability alone. But this is rapidly changing with the development of the science of Probabilistic Event Attribution (PEA), where super-ensemble climate models and statistical analysis are being used to attribute specific meteorological extremes to human influences on the climate system (Allen 2003, Stott et al., 2004, Stone et al. 2005, Pall et al. 2011, Otto et al. 2012 and Bindoff et al. 2013).

There is a lively debate in recent literature about the relevance of PEA to developments in climate policy negotiations under the UNFCCC. Allen and others argue that event attribution will be increasingly significant in guiding adaptation planning including the distribution of funds (Allen 2003, Pall et al. 2011, Stott et al. 2013), while Hulme argues against the utility of determining the fractional attributable risk of extreme events for such purposes (Hulme et al. 2011, Hulme 2014). Further, the ability to offer quantitative assessments of just how much anthropogenic climate change is responsible for any specific meteorological event raises the specter of moral responsibility, liability, and compensation for irreplaceable loss and unavoidable damages. Thus, James et al. argue that PEA is relevant to discussions about loss and damage while again Hulme argues to the contrary (James et al. 2014, Hulme 2014).

Both sides, however, address the relevance of PEA to discussions of loss and damage within the policy framework "pillar" concerned with adaptation, following decisions made at COP19 to provisionally locate the Warsaw International Mechanism for Loss and Damage (WIM) within the Cancun Adaptation Framework (CAF). Yet the specific shape and permanent institutional home of a UN policy mechanism for loss and damage is presently undetermined, in development, and scheduled for review and a decision in 2016.

We argue that attributing extreme weather events to climate change, by the methods of PEA and exemplified in the accompanying article by Mera et al., are ethically significant and have normative implications for pending policy decisions concerning WIM. In what follows we explain and then defend this position on two grounds.

First, the ability to attribute the occurrence of a particular extreme event to climate change is about events occurring today or in the recent past, not predictions about future events. The method is not particularly germane to actions undertaken with the aim of reducing social vulnerability to climate change, and thus not directly relevant to adaptation planning. So we can agree with Hulme's conclusions but draw an important corollary: to the extent that event attribution is not relevant to adaptation, so it is relevant to discussions of loss and damage. There are conceptual reasons to support the development of a mechanism for loss and damage into an independent pillar of the UNFCCC policy framework, on par with mitigation, adaptation, technology transfer, and financing.

This implication of developing loss and damage as an independent pillar is backed by a second set of specifically moral considerations. The causal attribution of harmful extreme events to climate change is relevant to the challenge of fostering healthy long-term international relations, which itself is likely a precondition for building the institutions necessary to respond appropriately to global environmental problems such as climate 
change. Some climate ethicists have called for developed nations to pay a "climate debt," or otherwise transfer wealth to the developing countries as a form of compensation for the harmful impacts brought about by climate change, and that this compensation is due on the basis of climate justice. Confidently attributing extreme events to anthropogenic influence on the climate system could support liability claims and thus provide evidence that compensation is due for the resultant harms.

We argue that while financial compensation is one form of restitution, and thus works towards the restoration of justice after a moral wrong, climate justice has other dimensions that PEA can contribute to, including important forms of recognition and reparation. Due to the grave and historic distributive injustices connected with climate change, the flourishing of humanity (i.e., human development and well-being) will depend on achieving political reconciliation between developed and developing nations, and ultimately moral repair between the people cohabiting a climate changed world. Our view is that PEA is able to make positive contributions toward this end.

\section{Policy Context}

At COP18 in Doha, a decision was taken pursuant of the Durban Platform for Enhanced Action recognizing "the need to strengthen international cooperation and expertise in order to understand and reduce loss and damage associated with the adverse effects of climate change, including impacts related to extreme weather events and slow onset events." 2 Yet, the issue of loss and damages became a central focus of negotiations only at COP19 in Warsaw, with the deeply contested decision to establish "the Warsaw International Mechanism for Loss and Damage, under the Cancun Adaptation Framework [and] subject to review at the twenty-second session of the Conference of the parties.... to address loss and damage associated with impacts of climate change."3

There had been broad agreement on the importance of the issue but developing countries wanted a new, independent mechanism while developed countries wanted it placed "under" the existing adaptation framework. Unsurprisingly, at the heart of the disagreement lay concerns about money. Negotiations nearly broke down until a deal was brokered to provisionally locate WIM under CAF with the promise of later review.

It's noteworthy that these negotiations did not involve demands of compensation, which has been called a "red-line" by the US and other developed nations who deny in any sense owing a "climate debt." But despite what may seem expedient for reaching agreement, we may still wonder: ethically what should WIM look like after the review period in 2016? Should it include provisions for compensation or other forms of redress for unavoidable economic damages and irreversible noneconomic losses? Developing

\footnotetext{
${ }^{2}$ http://unfccc.int/resource/docs/2012/cop18/eng/08a01.pdf\#page=21 (accessed July 30, 2014)

${ }^{3}$ http://unfccc.int/resource/docs/2013/cop19/eng/10a01.pdf (accessed July 30, 2014)
} 
countries are desperate for funds to advance mitigation, build adaptive capacity, and to address permanent loss and unavoidable damages due to climate impacts.

The allure of reaching an agreement in Paris on mitigation makes bracketing all discourse about compensation seem pragmatically attractive. Such "political realism" is additionally attractive to developed countries because this approach identifies emission reductions and climate justice as separate agendas that can be pursued independently (Posner and Weisbach 2010). But the outcome of any political negotiations can't "debunk" moral claims that developing nations may be due compensation for loss and damages caused by climate impacts for which others could be found responsible. If loss and damages resulting from extreme events can be attributed to anthropogenic climate drivers, which in turn can be attributed to those who have historically generated the greatest amount of greenhouse gas emissions, then we would have grounds supporting the claim that developed countries indeed do owe reparations, perhaps in the form of compensation. If so, and the climate negotiations were procedurally just, why should developing countries agree to climate policies that ignore what they justly deserve? In section (V) we discuss if making appropriate restitutions includes only compensation.

It is important to highlight that moral responsibility cannot be assigned just because the action of some parties, emitting greenhouse gases, can be robustly linked to extreme events that cause loss and damages. An increasing body of literature is dealing with additional conditions that need to be met in order to assign moral responsibility and even further conditions to incur compensation (e.g. Mueller et al., 2009). However, one necessary condition is that a causal link between the action and the loss can be established. We argue that PEA is an essential tool to make this link.

Despite the outcome negotiated in Warsaw, where WIM was provisionally located within CAF and issues of compensation were sidestepped, there are conceptual and moral reasons that an ability to attribute a fraction of the risk of actual and particular extreme events to anthropogenic climate change has significant bearing on two still undetermined questions of moral significance. First, should the WIM constitute an independent pillar of the UNFCCC policy regime? Second, should a mechanism for loss and damage include provisions toward compensation, or other duties of reparation, for loss and damages resulting from extreme weather events that are attributable to anthropogenic climate change? (Taraska 2013) We pursue answers to these questions in what follows.

\section{Definitions and Temporal Orientation}

To set out the ethical and normative relevance of PEA it will be useful to describe how mitigation and adaptation are commonly understood. Mitigation involves reducing of the magnitude of climate change itself and is accomplished by reduction of the drivers of climate change (e.g., reduced emissions). By contrast, adaptation fundamentally concerns reducing human vulnerability to the harmful impacts of climate change or increasing a system's resilience to climate change impacts. Adaptation strategies include changes to reduce harms caused by extreme events (e.g., enhancing costal storm barriers) and 
activities designed to reduce the risks posed by slow-onset changes (e.g., modifying agricultural practices).

The conceptualization of loss and damage is less well established. In particular, while the UNFCCC has published a working definition there is currently no discussion about a definition that could be agreed upon by the parties (UNFCCC 2013). Typically, however, "damage" refers to those harms caused by climate change impacts that are capable of being repaired or restored, while "loss" refers to harms caused by climate change impacts, either via extreme events or slow-onset phenomena, that are beyond repair and thus permanent. The kind of losses due to extreme events and slow-onset changes can include loss of human life, livelihoods, culture, customs, and territory, while reparable damages may befall a society's economy, material infrastructure, or social institutions.

Without doubt some climate impacts can cause significant harms, including loss and damages. Thus, anything that reduces the magnitude of climate change, i.e., mitigation, will reduce future loss and damages. Similarly, adaptation can reduce future loss and damages because as a society increases its adaptive capacity, thus becoming less vulnerable, thereby society is subject to fewer climate harms, including potential loss and damages. In sum, progress in mitigation and adaptation will reduce the amount of loss and damages due to climate change.

However, either now or in the future, we may be facing a magnitude of climate change capable of causing harmful impacts that neither mitigation nor adaptation can preclude. First, existing concentrations of greenhouse gases in the atmosphere already commit us to a certain amount of climate change and the degree of climate change to which we are already committed may cause harms, including loss and damages, in which case additional success in mitigation cannot prevent or reduce such loss and damages. Our hopes would turn to advances in adaptation.

But there may be limits to adaptation, in which case not all climate impacts could be successfully adapted to. There is a growing body of literature exploring the limits of adaptation (Adger 2009). "Limits to adaptation are a function of both the rate and magnitude of climate change, and adaptive capacity," according to Kline. ${ }^{4}$ Dow et al. define an adaptation limit "as a point at which an actor can no longer secure valued objectives from intolerable risk through adaptive action." (Dow 2013)

Thus, successful adaptation could protect us from harms, including loss and damages, arising from the climate change we are already committed to. But if we fail to mitigate climate change enough - measured against the criterion of keeping it within limits of adaptation - then harmful climate impacts may produce "residual" loss and damages, i.e., those which have not been avoided through mitigation or adaptation. Meteorological hazards pose a risk to society that is mediated "through complex political, social, and

${ }^{4}$ http://www.irinnews.org/report/98340/what-are-the-limits-to-climate-changeadaptation\%20 (accessed on Jul. 23, 2014). 
economic structures, which determine social vulnerability" as Hulme rightly points out, and the limits of our ability to adapt to climate change are not well understood and may change with future social and technological developments (Hulme et al. 2011, 765). But, as Kline describes, if the magnitude and rate of climate change outstrips our adaptive capacity, then we are open to harms from climate impacts that will count as residual loss and damage. By definition, no success in climate adaptation can diminish such residual loss and damages.

Conceptually, loss and damage are distinct from adaptation and mitigation, in the sense that there may well be residual loss and damages that cannot be successfully addressed by more robust engagement in and success with mitigation or adaptation. From this perspective, then, we have a prima facie reason for not locating WIM within CAF and which suggests alternatively, that a mechanism for addressing residual loss and damage should be developed as an independent pillar.

We note that without a capacity to attribute extreme events to anthropogenic climate change, the only loss and damages for which climate change could be found causally responsible would be those arising from slow-onset phenomena, such as sea-level rise. So only if we are able to attribute a particular extreme event to anthropogenic climate change, can it make any sense to talk about - as is commonly done - loss and damages due to climate impacts in the form of extreme weather events. And PEA is presently the best way to establish causal connections between greenhouse gas emissions and weather events because we have neither perfect observations nor perfect models, so we cannot exclude the possibility that the event could have occurred due to natural variability alone. PEA does allow us, however, to say how the likelihood of a given event occurring today has changed due to anthropogenic climate change. Therefore the use of "causality" in this context is the notion of a probabilistic cause - bringing about an increase in the probability of an event occurring - as, for example, when asserting that smoking causes cancer. It is not the notion of a deterministic cause (or set of causal conditions), which is to say, an occurrence that necessarily yields the event to which it is causally associated.

But if PEA enables the attribution of a particular extreme events to anthropogenic climate change, and we can assert that some particular event gives or has given rise to residual loss or damages, then we see that PEA enables us to attribute some residual loss and damages to anthropogenic climate change as, we have already said, is common in discussions of loss and damage. Thus the very possibility of making sense of attributing residual loss and damages to climate change impacts connected with extreme events also opens the possibility of assigning moral responsibility for the permanent and unavoidable harms caused by some extreme events. We postpone further discussion of climate justice until section (V).

So, the possibility of residual loss and damages supports the position that WIM should not be located in CAF. Furthermore, an ability to attribute an extreme event to climate change, via PEA, reveals another reason why a UN mechanism for loss and damage should not be located within the adaptation framework. Specifically, the methods for attributing an increased probability of a particular event of a given magnitude and meteorological state to climate change, and subsequently any residual loss and damage 
caused by the event, are designed to offer at least a partial and probabilistic explanation of the cause of that particular token extreme event. The methods of PEA are not designed to predict future occurrences of events of that type.

Attribution concerns only particular recent or presently occurring extreme events, thus a changed likelihood of events of this very same type today, occurring under a specific atmospheric regime. While in many cases the results of an attribution study and of a shortterm prediction may look very similar, indeed indistinguishable when the fraction of attributable risk is only due to thermodynamic changes of the climate system, an extreme event caused by anthropogenic climate change is also driven by atmospheric circulation which has been altered. Thus, the attribution result may not hint at the future since the circulation regime may well change further due to non-thermodynamic factors, which are more difficult - if not impossible - to predict.

Accurate predictions of extreme events are forward-looking and include predictable changes in the circulation (when possible) and thus could deliver information that is useful for adaptation planning. Whereas event attribution is backward-looking: events of a given magnitude are compared under different models to assess the fractional increase in the probability of having this particular extreme weather event actually occur, crucially including unpredictable atmospheric regimes. Whereas this fractional increase in risk of some actual and particular heat wave occurring is arguably attributable to anthropogenic greenhouse gas emissions, such information is not useful in planning, or preparing for heat waves of this type, thus not particularly germane to planning and enhancing climate adaptation. This is so because climate adaptation, as defined above, is concerned with actions designed to reduce social vulnerability to future harmful climate impacts resulting from events of some particular type. Adaptation to reduce harms from extreme weather requires only that we can predict future extreme events will occur more frequently and with greater intensity. Event attribution is not designed for making such predictions.

\section{Response to Hulme's Analysis}

As mentioned above, Hulme also argues against the significance of event attribution

for planning and funding decisions about adaptation. In this section we consider four of his arguments. Just where Hulme's arguments are convincing, however, we find reasons to believe that PEA is significant to on-going discussions about loss and damage. While PEA will most likely have additional applications, we will focus on its relevance for loss and damage, as the normative and ethical implications are easy to see in context of the UNFCCC framework.

First, according to Hulme, proponents of PEA "confuse" guiding adaptation with compensation for loss and damage. He argues that "using PEA in adaption funding allocations would imply that the purpose of international adaptation finance is to compensate for damages caused by anthropogenic climate change," but instead the purpose of adaptation finance is building adaptive capacity, thus reducing vulnerability, and therefore it would be a mistake to employ PEA in adaptation funding allocations (Hulme 2011: 765). Indeed, the issues are distinct and the purpose of adaptation funding is 
to reduce social vulnerability and build resilience. The bearing that PEA has for discussions of loss and damage, we argue, is to make sense of attributing to climate change particular weather events that generate residual loss and damages and since this should not be confused with adaptation planning, WIM should be treated as an independent policy mechanism, not subsumed within the adaptation framework.

Second, Hulme also rightly asserts that adaptation funding is needed most where "vulnerability to meteorological hazard is high, not where meteorological hazards are most attributable to human influence" (Hulme 2011: 765). Again, we agree. PEA is relevant to claims about responsibility for meteorological hazard in the way discussed in the introduction and section (V), not for estimating relative degrees of social vulnerability to climate impacts including exposure to such hazards. We should not confuse the increased likelihood that a weather event of particular magnitude will strike a society with an accounting of how vulnerable society is to harms which could be caused by events of that type. Additionally, we have acknowledged that whether an extreme meteorological event can lead to damages depends not only on the likelihood of the event occurring but also on the preparedness of the society.

Third, when Hulme claims that proponents of PEA fail to discriminate hazard from risk, he rightly identifies that PEA's focus is on meteorological hazards, not on the impacts of socially mediated risk events (Hulme 2011, p.765). We can agree and find an additional reason that loss and damage should be an independent pillar because it concerns the attribution of meteorological hazards, not the mediated risks that can be affected by adaptive measures. Adaptation is about reducing socially mediated risk, as Hulme describes, in the future while PEA is not. Instead, as we argued in the previous section, PEA enables the attribution of residual loss and damage that have already happened or that may happen in the future (but only once the extreme weather event in question has already occurred) via the attribution of particular weather hazards, to human influence on the climate system. PEA is about attribution in the present, not predicting increased frequency in the future.

While most event attribution studies only address the hazard and not the risks of mediated impacts, in principle PEA could be applied to the attribution of impacts of meteorological hazards. For example, excessive rain as such does not cause loss and damage but flooding and inundation does. Therefore a step assessment (from meteorology, over hydrological conditions, to direct and indirect socio-technical and socio-economic impacts) of the attributable risk with respect to the impacts would have to be done (Huggel et al. 2013). Risk assessment from hazards to impacts is a well-established methodology comprising hydrology, infrastructure analysis, ecosystems and direct and indirect socioeconomic impacts which so far has not been regularly integrated in the assessment of attributable risk. But Pall et al. (2011) and Stone et al. (2013) have demonstrated that PEA can include this methodology. In this issue, Mera et al. explore this method and address impacts of the meteorological hazard as well as the hazard itself and thus provide an example of how the attribution of residual loss and damage could be done. Risk is a combination of hazard and vulnerability with "attributable risk due to anthropogenic climate change" defined in the literature as the relative change in the hazard conditioned on no change in the vulnerability (Bindoff et al. 2013). 
Finally, consider that Hulme objects to PEA generally on the grounds that it still "needs to be demonstrated that the models used can adequately represent, at the appropriate spatial scale, the characteristics of the weather extreme under study" (Hulme 2014, 8-9). This objection is relevant because if PEA were not applicable at the relevant scale, then its relevance pursuant an accounting for loss and damages would be significantly undercut. He is right that model evaluation is crucial to event attribution and a prerequisite of every event attribution study in combination with the actual definition of the event to attribute.

For every study there are four possible outcomes: global warming increased the likelihood of the event, it did not play a role in the event, it reduced the likelihood of the event, or the model was unable to reproduce the event. In this issue, Mera et al. give a good example of a study first analyzing observed temperature trends and records and analyzing the models ability to reproduce these trends and then, as a second step (cf. figure 2 in Mera et al) -- directly addressing Hulme's concern -- analyzing the circulation pattern. Correlating the temperatures and geopotential height in the model and observation shows very well how the model is able to simulate not only the temperatures but that it actually does this at the right scale for the right reasons: the atmospheric blocking conditions over the Western US and also the wave structure of the height over California and the West Atlantic.

To review this section, we have seen Hulme offer four arguments against the relevance of event attribution studies for climate policies under the UNFCCC. Specifically, he has argued against the relevance of event attribution for developing adaptation policy. In our analysis, we found that the success of his arguments supported our position that while attribution science is relevant to loss and damage, it is not applicable in the particular context of adaptation planning. This negative view supports our positive claim that loss and damage policy should be pulled out of CAF and developed as an independent policy pillar.

\section{Climate justice}

In closing we offer a second set of reasons why PEA is relevant to discussions of loss and damage and, in particular, if WIM should include provisions for climate reparations, or the making of amends, connected to moral responsibility and climate justice. Of course, talk about compensation, in particular, has proven decidedly problematic in reaching international agreement on climate policy (Vidal 2013). The basic claim, however, is compelling from the moral perspective: if one causes harms to another without justification, then morally - as we noted section (II), only if other conditions are satisfied - one may owe reparations. Arguably, developed countries have caused unjustified harms to others through their overuse of Earth's capacity to absorb carbon emissions (Shue 1993). One form reparations can take is financial compensation to the victim of harms unjustly suffered.

Consider what appears to be a moral dilemma: does the good of an international agreement on emissions reductions morally justify ignoring consideration of past injustices, 
in which some are responsible for the harms that befall others? Perhaps the only way to reach an emissions agreement, a good for all, is for grave climate injustices suffered by some to remain unaddressed. Framed this way, it appears that demands for climate justice operate as a hurdle to reaching an international agreement. Should we serve justice for the few or promote the good of all?

Our approach to this dilemma is to suggest how attributing extreme events, and at least some subsequent loss and damages, to climate change can advance climate justice and the prospects for international cooperation without necessarily requiring that developed nations pay financial compensation. The key is recognizing that legitimate forms of justice extend beyond questions of distribution or even retribution, that a specifically restorative justice - a dimension of justice that moves toward reconciliation by returning dignity and respected agency - can include claims for something other than compensation, including important forms of acknowledgement and recognition. In the long-term realizing climate justice in these forms might be a prerequisite to the provision of monetary compensation for loss and damage on the grounds of distributive justice.

There is a vast literature on restorative justice and the crucial role of recognition in both bringing about and remedying injustices. Consequently, the varied and subtle issues in play extend well beyond what we can fully address in this article. In what follows, then, our goal is to identify the framework of debate in which our claims about the relevance of PEA to issues of loss and damage and climate justice are to be understood.

In the past twenty-five years, the struggle for recognition of identity and difference has become a crucial component of justice struggles worldwide. Correspondingly, there has been significant debate concerning relations between the paradigms of (a) justice in distribution and (b) justice in recognition (Fraser and Honneth 2003). Traditionally, redistributive justice focuses on varied socio-economic status and unequal development pathways while recognition justice focuses on historical and institutional racial discrimination. As basic approaches to different dimensions of justice, a core debate in the literature has concerned how to understand the relationship between the two.

Developing one influential view, Honneth argues that recognition is the deeper issue and as such, recognition actually operates prior to issues of distribution. So he reduces issues and injustices concerning distribution to failures of recognition, maintaining that the latter are both in theory and as a matter of cause, prior to the former (Honneth 2004). What this means is that, in general, a case of distributive injustice is properly understood in terms of some failure for some people to be justly recognized and that such failures of recognition are phenomena in the world that bring about, or result in, an unjust distribution of goods.

On the other hand, Fraser presents a so-called "bivalent" approach. She maintains that achieving justice requires both redistribution and recognition, that the two ways of understanding injustice are in fact inseparable in the sense of being co-original and interpenetrating; one is neither prior to nor reducible to the other. She stresses that "only by articulating recognition and redistribution can we arrive at a critical-theoretical 
framework that is adequate to the demands of our age" (Fraser 1995, italics added). More recently, environmental philosophers such as Figueroa have been adopting a bivalent approach to questions of environmental justice, including climate justice, which "encourages theorists to incorporate cultural... and locational relations into the study of our environments, broadening the environmental justice debate" (Figueroa 2003).

Our approach in this paper is to propose that the status of those who suffer loss and damage due, in particular, to extreme events is not fully represented in terms of distributive injustice. Our view is that being the subject of these harms constitutes a substantive and significant difference in identity, compared to those who may suffer comparable harms due to natural variability alone, and thus this identity morally must be recognized as such. Failure to do so is not primarily a distributive injustice but rather is a failure of justice in recognition. Achieving due recognition plays an important role in restorative justice. Both are important but often under-recognized dimensions of environmental justice generally, and in discussions of climate justice, specifically.

Those who suffer loss and damages due to extreme events caused by anthropogenic climate change experience loss and damage that is attributable to human interference with the climate system. It is not just "hard luck". If this is true, then it must be acknowledged. Without an ability to attribute these significant loss and damages to climate change those who suffer have no different standing morally - are not recognized as existing in a different, a moral relationship - than those who suffer harms from exposure to simply natural hazards. But if the harms are different in origin - and we'd need a science of event attribution to know this - then they are different in their basic moral property: they matter differently.

One way they matter differently is that victims of harmful climate impacts can be recognized and identified as people who are paying part of the price for our collective failure to prevent dangerous climate change. They are not just unfortunate victims of natural weather variation. The harms they suffer can be recognized as arising from activities that are at least arguably acknowledged as morally wrong; the loss and damage they suffer will be recognized as originating at least in part from human moral failings, from actions that are wrong even if those responsible are not blameworthy and thus may not necessarily be liable to pay compensation or otherwise effect redistribution. Such identification and acknowledgment is significant and meaningful to the victims of what are moral wrongs, rather than victims of natural chance, and as such this recognition constitutes a morally significant a form of respect for humanity.

This form of recognition has practical significance. Our premise is that successfully addressing anthropogenic global environmental problems will require high levels of international cooperation and that while climate change receives the most attention today, there are and will be others, including nitrogen deposition, biodiversity loss, and human population growth (Rockström et al. 2009). According to Gardiner's influential analysis, climate change is a "perfect moral storm," a confluence of independently significant moral shortcomings, one of which is institutional inadequacy. Major contemporary institutions, including dominant social, political, and economic institutions, simply are not capable of 
carrying out the work of responding well to intergenerational, global environmental problems, including the climate crises (Gardiner 2013).

Ultimately, we'll need to build institutions that are appropriate to the challenges facing humanity in the Anthropocene. This will require high, perhaps unprecedented, levels of international cooperation. But there is a hurdle to achieving high levels of international cooperation in a world where people in some countries have suffered grave and justified harms, including significant loss and damages, attributable to phenomena that people from other countries are responsible for. We postulate that the degree of international cooperation requisite to build institutions appropriate to address the global and intergenerational environmental problems will depend upon achieving political reconciliation between the developing countries (who will suffer first, suffer most, and bear least historic responsibility) and the developed countries (who will likely suffer less in the short term but bear most historic responsibility).

Climate injustices require restitution, which aims at repairing the victim. In some circumstances, monetary compensation may be a sufficient form of moral repair and can serve to move the parties forward toward reconciliation. It's not obvious, however, that compensation is always necessary. ${ }^{5}$ The concern is with conditions necessary for moral repair, including political reconciliation between those who suffer injustices and those responsible for not preventing them. What happens after a moral failure, given some form of injustice has occurred? How can parties on both sides of an injustice move forward? How can they repair relationships in the direction of becoming morally adequate to foster reconciliation and future cooperation? Moral repair involves victim identification, acknowledgement of wrongdoing, and the making of amends which may or may not involve forms of compensation (Walker 2006).

We believe that the form of identity recognition discussed herein, i.e., as persons who suffer loss and damages attributable to anthropogenic climate change, plays an important role in the possibility of achieving restorative justice and that the science of PEA can play an important role securing such recognition. Hence, our position is that PEA could make a significant contribution to moral repair and the conditions for achieving political reconciliation between the developed and developing world in the wake of the ravages of climate change.

\section{Conclusion}

The UNFCCC is the largest organized, international, institutional response to the existential threat of anthropogenic global climate change. Climate mitigation remains a moral priority, as the overall well being of humanity depends on it. Adaptation to a changing environment is also morally urgent; increasing resilience and reducing

${ }^{5}$ Because the injustices associated with climate change that receive the most attention are distributional, the most common conception of due reparations or redress for these wrongs is redistributional. By advocating recognitional and restorative justice we don't deny that compensation may be due for unjust climate harms. 
vulnerability to climate change we cannot avoid is essential to reducing harm. Perhaps for the same reasons we should work to reduce human vulnerability to environmental harms regardless of their cause, in which case a science of weather event attribution would not be relevant to decisions about where and how to distribute adaptation funding. Many adaptation theorists embrace this broader conception and advocate adaptation to be "mainstreamed" into human development planning.

In any case, it is important to recognize that not all harms people suffer as a result of exposure to environmental hazards are the same morally. Some of the harms from extreme weather events could occur independently of any human influence on the climate system while some such harms, including residual loss and damages, are attributable to anthropogenic climate change. We have argued that a science of weather event attribution is both conceptually and morally relevant to issues of residual loss and damage and, subsequently, to decisions concerning the relevant UN climate policy mechanism.

\section{Author contribution}

AT and FELO developed the idea and wrote the paper together. 